\title{
European and Asian Pears: Simple Sequence Repeat-Polyacrylamide Gel Electrophoresis-based Analysis of Commercially Important North American Cultivars
}

\author{
Ashok K. Ghosh ${ }^{1}$ and Lewis N. Lukens ${ }^{1}$ \\ Department of Plant Agriculture, University of Guelph, Guelph, Ontario, \\ Canada N1G $2 \mathrm{Wl}$
}

\section{David M. Hunter \\ Agriculture and Agri-Food Canada and Department of Plant Agriculture, University of Guelph, Vineland Station, Ontario, Canada LOR 2EO}

\author{
Judith N. Strommer ${ }^{2}$ \\ Department of Plant Agriculture, University of Guelph, Guelph, Ontario, \\ Canada N1G 2W1
}

Additional index words. cultivar identification, molecular markers, Pyrus, Rosaceae

\begin{abstract}
The genus Pyrus (pear) includes species and cultivars of great diversity. We have tested the feasibility of a polyacrylamide gel eletrophoresis (PAGE)-based +/- simple sequence repeat (SSR) screen as a means of defining relationships amongst pears of commercial importance in North America. The screen included 28 pear accessions, including economically important cultivars, numbered selections from breeding programs and interspecific hybrids. It relied on $18 \mathrm{SSR}$ primer pairs, each of which produced polymorphic banding patterns in all the genotypes examined. Fragments were scored for presence or absence within genotypes. The results show that amplification and analysis of a small number of SSR loci enable identification of cultivars and reasonable definition of genetic relationships in North American pears. Seven primer pairs were sufficient to distinguish the 28 pear cultivars. Analyses using both distance and parsimony criteria grouped cultivars in a manner consistent with known pedigrees and sites of origin.
\end{abstract}

The genus Pyrus, containing $>22$ species, is a highly diverse source of pome fruit cultivated throughout the temperate world. Cultivars and rootstocks used for commercial production are maintained true-to-type through vegetative propagation. In nature, however, pear is an out-crossing perennial, leading to high levels of heterozygosity and allelic diversity within the genus. Pyrus communis L., the common (European) pear, encompasses $>5000$ cultivars (Monte-Corvo et al., 2001), only a small percentage of which are cultivated commercially (Bell et al., 1996). Members of this species are morphologically distinguishable from the

Received for publication 1 Nov. 2005. Accepted for publication 3 Dec. 2005. We gratefully acknowledge the financial support of the Ontario Tender Fruit Producers' Marketing Board, Kraft Canada Inc., the Food Science Biotechnology Centre of the University of Guelph, and the National Science and Engineering Research Council. The assistance of Agriculture and Agri-Food Canada, in providing plants as well as matching funds for this research, is greatly appreciated. We would also like to thank the anonymous reviewers of this manuscript for their excellent suggestions.

${ }^{1}$ Current address: Agriculture and Agri-Food Canada, 4902 Victoria Avenue North, PO 6000, Vineland Station, Ontario, Canada LOR 2E0.

${ }^{2}$ Author for correspondence; e-mail jstromme@uoguelph.ca. major Asian cultivated species, $P$. pyrifolia (Burm.) Nak. [syn. P. serotina (Rehd.)].

Early efforts to identify cultivars by means of phenotypic data (Kikuchi 1948; Shen 1980; Westwood 1982) proved useful for a limited number of cultivars in certain conditions. However, the phenotypic variability seen amongst accessions of tree fruit grown in different areas with slightly different environments and production practices demonstrates a number of problems with that approach (Kresovich and McFerson 1992, Hokanson et al., 1998). Isozyme markers have also been used for analyses of genetic relatedness. They tend to detect a relatively low level of polymorphism and may depend on the physiology of the plant at the time of analysis (Arulsekar et al., 1986; Chevreau et al., 1997; Chung and Ko 1995; Messeguer et al., 1987). Since the early 1990s, molecular (DNA) markers have become popular tools for investigating the origins and extent of genetic diversity within a population.

For pears, DNA-based markers are particularly useful for germplasm identification, diversity analysis and verification of rootstock identity. DNA analyses, including the use randomly amplified polymorphic DNA (RAPD) and simple sequence repeat (SSR) markers, have previously been used for molecular fingerprinting in pear (Botta et al., 1998; Monte-Corvo et al., 2001; Oliveira et al., 1999; Yamamoto et al., 2001, 2002a). Relationships among cultivars of Japanese (Iketani et al., 2001, Yamamoto et al., 2001, 2002a, 2002b, 2002c) and European (Botta et al., 1998; Oliveira et al., 1999; Monte-Corvo et al., 2001) pears have been investigated, but little information is available on the genetic relationships amongst cultivars of commercial importance in North America, both those developed there and those introduced from Europe and Asia.

The present study evaluates the genetic diversity and relationships of 28 cultivars across 4 species of the genus Pyrus including 2 interspecific hybrids. This study focused on cultivars originating in North America, Asia, and Europe, and currently grown in North America either commercially or for breeding purposes. At the same time, the method itself was evaluated by including some recentlyintroduced cultivars with well-documented pedigrees, to test the concordance of known relationships with inferred relationships.

Amplification and analysis of a small number of SSR loci permitted identification of cultivars and reasonable definition of genetic relationships in North American pears. A small set of SSR markers which uniquely identify each cultivar have been identified. Genetic relationships predicted by SSR patterns are largely congruent with expectations from geographic origin and available pedigree information. Cultivars generated in Ontario grouped together (e.g., 'AC Harrow Gold', 'AC Harrow Crisp', 'Harvest Queen', and 'Harrow Delight'), as did selections derived from shared interspecific parents (NY10352 and NY10353). Japanese cultivars grown in North America were genetically distinct from P. communis and other Pyrus species.

\section{Materials and Methods}

In total, 28 pear cultivars were selected from a collection of $>200$ maintained in the germplasm collections of Agriculture and AgriFood Canada and the University of Guelph at Vineland Station in southern Ontario (latitude $41^{\circ} 10-12 ' \mathrm{~N}$, longitude $\left.79^{\circ} 21-24^{\prime} \mathrm{W}\right)$. They were chosen primarily for their commercial or breeding importance; a few cultivars of welldocumented origins also provided a means of assessing the experimental approach. The origins and Latin names of each of the cultivars are presented in Table 1 .

Based on initial comparisons of DNA extracted from young and mature leaves, newly expanded young leaves were collected shortly after bud break in the early spring, frozen in liquid nitrogen and stored at $-80^{\circ} \mathrm{C}$ until DNA was isolated. Genomic DNA was extracted using a DNeasy Plant Maxi Kit (Qiagen Inc., Mississauga, Ont.). About $100 \mathrm{mg}$ of frozen leaf tissue was homogenized in liquid nitrogen before addition of extraction buffer. A minimum of two extractions was performed for each cultivar. Concentrations of DNA in the extracts were determined by $\mathrm{A}_{260}$ absorption or $\mathrm{A}_{260} / \mathrm{A}_{280}$ ratios, and the quality confirmed by electrophoresis of samples alongside known 
Table 1. List of pear cultivars used in this study, with available information regarding pedigrees and geographic origin.

\begin{tabular}{|c|c|c|c|c|}
\hline No. & Cultivars & Scientific name & Pedigree/known background & Origin \\
\hline 1 & Nijisseiki & Pyrus pyrifolia Burm. & Chance seedling & Japan \\
\hline 2 & Hosui & Pyrus pyrifolia Burm. & $($ Kikusui $\times$ Yakumo $) \times$ Yakumo & Japan \\
\hline 3 & Kosui & Pyrus pyrifolia Burm & Kikusui $\times$ Wase Kozo & Japan \\
\hline 4 & Niitaka & Pyrus pyrifolia Burm & Amanogawa × Imamura-Aki & Japan \\
\hline 5 & Shinko & Pyrus pyrifolia Burm & Seedling of cultivar Nijisseiki & Japan \\
\hline 6 & Anjou & Pyrus communis L. & Europe (France) & \\
\hline 7 & Bartlett & Pyrus communis L. & Chance seedling & Europe (England) \\
\hline 8 & Bosc & Pyrus communis L. & Europe (Belgium) & \\
\hline 9 & Clapp Favorite & Pyrus communis L. & Flemish Beauty $\times$ Bartlett & Europe \\
\hline 10 & Flemish Beauty & Pyrus communis L. & Chance seedling & Europe (Belgium) \\
\hline 11 & Magness & Pyrus communis L. & Seckel seedling $\times$ Comice & U.S. (Md.) \\
\hline 12 & Moonglow & Pyrus communis L. & U.S. (Mich.) $437 \times$ RCW & U.S. (Md.) \\
\hline 13 & Obican Vodenac & Pyrus communis L. & East Europe (Yugoslavia) & \\
\hline 14 & Timpurii de Dimbovita & Pyrus communis L. & East Europe & \\
\hline 15 & Harrow Delight & Pyrus communis L. & Bartlett $\times$ Purdue $80-51^{z}$ & Canada (Ont.) \\
\hline 16 & Harvest Queen & Pyrus communis L. & Bartlett $\times$ Michigan $572^{z}$ & Canada (Ont.) \\
\hline 17 & AC Harrow Crisp & Pyrus communis L. & Bartlett $\times$ US 56112-146 & Canada (Ont.) \\
\hline 18 & AC Harrow Gold & Pyrus communis L. & Harrow Delight $\times$ Harvest Queen ${ }^{\mathrm{x}}$ & Canada (Ont.) \\
\hline 19 & NY10352 & Pyrus hybrid & P. communis $\times(P$. communis $\times P$. ussuriensis $)$ & U.S. (N.Y.) \\
\hline 20 & NY 10353 & Pyrus hybrid & P. communis $\times(P$. communis $\times P$. ussuriensis $)$ & U.S. (N.Y.) \\
\hline 21 & Kieffer & Pyrus hybrid & P. pyrifolia $\times P$. communis & U.S. (Pa.) \\
\hline 22 & OHF 69 & Pyrus communis L. & Old Home $\times$ Farmingdale & North America \\
\hline 23 & OHF 87 & Pyrus communis L. & Old Home $\times$ Farmingdale & North America \\
\hline 24 & OHF 333 & Pyrus communis L. & Old Home $\times$ Farmingdale & North America \\
\hline 25 & Winter Nelis & Pyrus communis L. & Europe (Belgium) & \\
\hline 26 & Catillac & Pyrus communis $\mathrm{L}$ & Europe (France) & \\
\hline 27 & PI 312151 & Pyrus ussuriensis M. & Asia (Uzbekistan) & \\
\hline 28 & Pyrus fauriei & Pyrus fauriei Schneid. & Korea & \\
\hline
\end{tabular}

${ }^{\mathrm{z}}$ Quamme and Spearman, 1983.

yHunter et al., 2002a.

${ }^{x}$ Hunter et al., 2002b.

quantities of standards. The samples were diluted to $5 \mathrm{ng} \cdot \mu \mathrm{L}^{-1}$ with TE buffer $(10 \mathrm{mM}$ Tris, $1 \mathrm{~mm}$ EDTA pH 8.0) and kept at $-20{ }^{\circ} \mathrm{C}$ for subsequent PCR amplification.

In total, $26 \mathrm{SSR}$ primer pairs from apple (Gianfranscheschi et al., 1998; Guilford et al., 1997), peach (Sosinski et al., 2000), and pear (Yamamoto et al., 2002a, 2002b, 2002c) were tested, using five cultivars randomly selected from those under study. Based on the reproducibility of polymorphic patterns obtained with these cultivars, 18 primer pairs were selected for analysis of the 28 selected genotypes. The names and sources of the primers, along with annealing temperatures, are presented in Table 2.
PCR reactions were performed in a Techne Flexigene DNA thermal cycler (Techne Inc., Minneapolis, Minn.). Reaction mixtures contained $10 \mathrm{ng}$ of genomic DNA, $10 \mu \mathrm{L}$ Taq PCR Master Mix (Qiagen Inc.), and 50 pmol of each primer brought to a total volume of $20 \mu \mathrm{L}$ with nuclease-free distilled water. Amplifications were carried out for 35 to 40 cycles, depending on the primer pair. In general, the amplification protocol consisted of initial denaturation for 2 min at $94{ }^{\circ} \mathrm{C}$ followed with $1 \mathrm{~min}$ at $94{ }^{\circ} \mathrm{C}, 1$ $\mathrm{min}$ at the appropriate annealing temperature (see Table 2), and $2 \mathrm{~min}$ at $72^{\circ} \mathrm{C}$, with a final elongation step of $7 \mathrm{~min}$ at $72^{\circ} \mathrm{C}$. Three primer sets (CH01F02, CH02B10, and KA4b) required touchdown protocols (Mellersh and Sampson,
1993) for optimal amplifications. In those cases, the annealing temperature was reduced by 0.5 or $1.0^{\circ} \mathrm{C}$ per cycle for the initial 6 or 8 cycles, followed with 35 to 40 amplification cycles at the target annealing temperature. The amplified products were separated by vertical polyacrylamide gel eletrophoresis (PAGE) in a $22 \mathrm{~cm}$ tall gel using $10 \%$ polyacrylamide (acrylamide: bis $=29: 1$ ). The gels were stained with ethidium bromide $\left(1 \mu \mathrm{g} \cdot \mu \mathrm{L}^{-1}\right)$ for $15 \mathrm{~min}$ followed with 20 minof destaining in water. To ensure reproducibility, all PCR reactions were conducted at least twice using DNA samples from different extractions.

The lengths of all amplified fragments obtained with 18 primer pairs and 28 cultivars

Table 2. Primer sets used in this study.

\begin{tabular}{|c|c|c|c|c|}
\hline Primer & Source & $\begin{array}{c}\text { Annealing } \\
\text { temp } \\
\left({ }^{\circ} \mathrm{C}\right)\end{array}$ & $\begin{array}{l}\text { Fragments } \\
\text { (no.) }\end{array}$ & $\begin{array}{c}\text { Fragment } \\
\text { size } \\
\text { (bp) }\end{array}$ \\
\hline$\overline{\mathrm{CH} 01 \mathrm{~F} 02}$ & Gianfranceschi et al., 1998 & $64 \sim 58\left(-1^{\circ} \mathrm{C} /\right.$ cycle $)$ & 49 & $116-399$ \\
\hline $\mathrm{KA} 4 \mathrm{~b}$ & Yamamoto et al., 2002a & $58 \sim 54\left(-0.5^{\circ} \mathrm{C} /\right.$ cycle $)$ & 34 & $77-439$ \\
\hline NB105a & Yamamoto et al., 2002b & 47 & 52 & $128-482$ \\
\hline NB109a & Yamamoto et al., 2002b & 55 & 34 & $140-375$ \\
\hline NH001c & Yamamoto et al., 2002c & 48 & 49 & $103-403$ \\
\hline NH013a & Yamamoto et al., 2002c & 55 & 45 & $149-486$ \\
\hline NH021a & Yamamoto et al., 2002b & 55 & 55 & 134-397 \\
\hline NH025a & Yamamoto et al., 2002b & 51 & 33 & $78-387$ \\
\hline $\mathrm{NH} 027 \mathrm{a}$ & Yamamoto et al., 2002b & 47 & 54 & $118-463$ \\
\hline NH029a & Yamamoto et al., 2002b & 55 & 42 & $87-382$ \\
\hline NZ02b1 & Guilford et al., 1997 & 50 & 46 & $160-564$ \\
\hline NZ05g8 & Guilford et al., 1997 & 50 & 22 & $102-345$ \\
\hline
\end{tabular}

${ }^{2}$ Number of different fragments produced amongst all pear genotypes. 


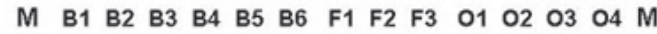

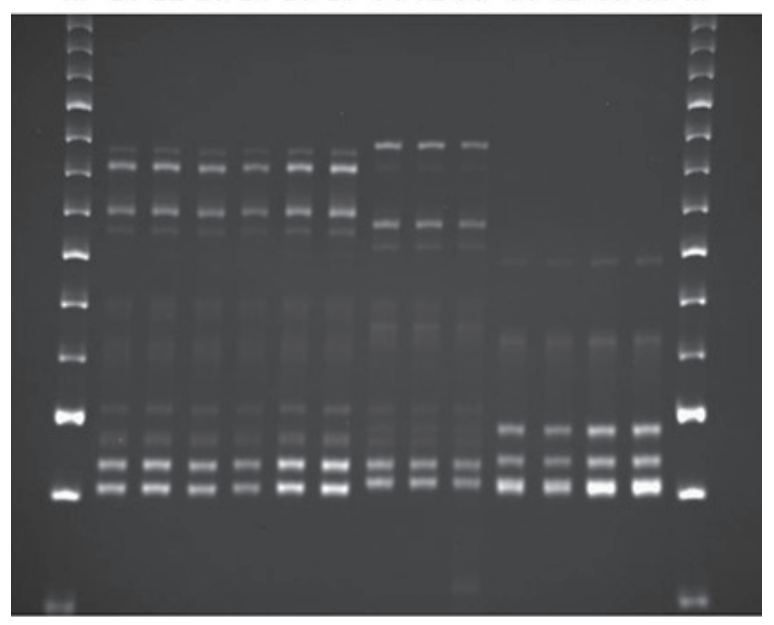

maximum parsimony criteria, implemented with the MIX program of PHYLIP using default settings. All fragments were considered characters of equal weight. Support for clades within the parsimony tree was estimated with bootstrap resampling (1000 permutations).

\section{Results and Discussion}

While extractions from leaves harvested in the spring yielded high-quality DNA, older toughened leaves did not provide DNA suitable for amplification. All primerpair/sample combinations produced identical fragments in

Fig. 1. Polyacrylamide gel containing ethidium bromide-stained simple sequence repeat (SSR) fragments obtained from multiple accessions of 'Bartlett' (B1-B6), 'Flemish Beauty' (F1F3), and 'Old Home' (O1-O4) with primer pair NZ05g8, demonstrating the absence of detectable intracultivar polymorphisms.

were calculated using Geldoc software (Perkin Alpha Innoteck Corp., San Leandro, Calif.), then verified visually for accuracy, comparing every fragment against standard $25 \mathrm{bp}$ molecular size markers (Invitrogen Canada Inc., Burlington, Ont.).

All unambiguous fragments were scored as either present (1) or absent (0) for each genotype in the data table. A matrix of distances (D) was constructed, using the percentage of fragments that differed between each genotype:

$D=\left[1-\left(\frac{\text { fragments shared }}{\text { fragments scored }}\right)\right]$

Based on the distance measures, the Fitch package in PHYLIP (Felsenstein, 2000) was used to generate trees, which were evaluated using the Fitch-Margoliash algorithm (Fitch and Margoliash, 1967) implemented in PHYLIP. The optimal tree was selected from 10 runs. Each run used the default parameters and a different order of cultivars in constructing trees. A second tree was estimated by

$\begin{array}{lllllllllllll}1 & 2 & 3 & 4 & M & 5 & 6 & 7 & 8 & 9 & 10 & M & 12\end{array}$ two or more amplifications. The electrophoretic system could generally resolve 100 to $300 \mathrm{bp}$ fragments differing by $2 \mathrm{bp}$, as determined from standards of known lengths (data not shown). Eighteen primer pairs which produced useful polymorphic fragments within the sample collection were used in the study (Table 2).

To test for potential within-cultivar variations, DNA from cultivars for which multiple accessions were available were examined using the primer pair NZ05g8 (Guilford et al., 1997). There were no within-cultivar differences seen among six accessions of 'Bartlett', three accessions of 'Flemish Beauty', and four accessions of 'Old Home' (Fig. 1). A comparison of fragments for the one known set of progeny (Clapp Favorite) and parents (Flemish Beauty and Bartlett) demonstrated that all major fragments in the progeny cultivar were detectable in one or both parents (data not shown).

Although information on expected product sizes was not available for most combinations of primer pair and cultivar, six such fragment sizes were available. In all but one of the six cases the expected products were seen: CH01F02 (Gianfranceschi et al., 1998) amplified fragments of 163 and $176 \mathrm{bp}$ from 'Bartlett' and 165 bp from 'Hosui'; K4Ab (Yamamoto et al., 2002a) amplified fragments of 95 and 107 bp from 'Hosui', $97 \mathrm{bp}$ from 'Bartlett', and 97 and $107 \mathrm{bp}$ from 'Niitaka'. The exception was the combination of K4Ab with 'Winter Nelis', which failed to produce the expected fragment of $137 \mathrm{bp}$ (Yamamoto et al., 2002a).

The amplification products of the NZ05g8 primer pair for all 28 cultivars (Fig. 2) illustrates the variability found in amplified PCR fragments. Overall, scorable fragment lengths ranged from 77 to $500 \mathrm{bp}$. Some primer pairs generated high molecular weight fragments (>500 bp), which were difficult to score and compare accurately; these were not included in the analysis. For a single individual the number of scorable fragments obtained with a single set of primers ranged from one to 16 . Microsatellite amplifications generated nearly 800 different readable fragments with an average of 42 fragments per marker.

The 18 SSR primer pairs provided sufficient information to distinguish all 28 cultivars from one another (Table 3). Only one $177 \mathrm{bp}$ fragment, detected by the RLG1-1 primer pair, was shared by all cultivars under study. A 108 bp fragment obtained with the NH010a marker was found in all the cultivars except 'Kieffer', 'Catillac' and the rootstock selection OHF 69. The primer pair CH01F02, distinguishing only three cultivars, offered the least information, while NH006b1 produced unique identifying markers for nine cultivars within our sample. A total of seven primer pairs (NB105a, NB109a, NH001c, NH006b1, NH013a, NZ02b1, and PS12A02) was sufficient to effectively differentiate all 28 cultivars. These SSR primer pairs are therefore potentially powerful tools for cultivar identification as well as breeding and genetic studies of pear.

In our analysis, we can distinguish neither allelic pairs nor individual loci; each fragment is counted as a character of the cultivar from which it was amplified. As a result, an SSR primer pair with a large number of fragments has a greater weight in cultivar classification than an SSR primer pair with a small number of fragments. In addition, heterozygous loci counted as two separate characters. Many of the primer-cultivar combinations produced two fragments that were abundant and similar in size. A second parsimony tree was generated, based on these potentially allelic fragments. Bootstrap support for the clades generated in this way, however, were lower than for those obtained in the original analysis (data not shown). The decreased bootstrap support

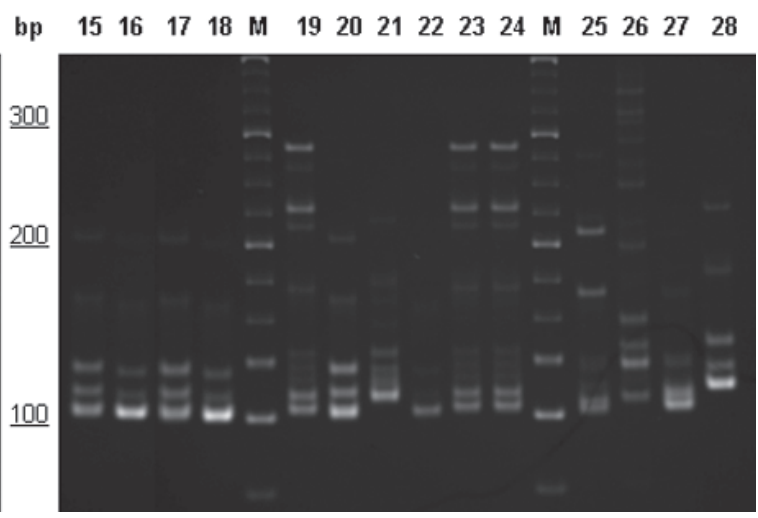
for groups based on this subset of the data argued against preselection of fragments when, as in the current case, fragments are not assignable to specific loci.

Relationships among the 28 pear cultivars were inferred using both distance (Fig. 3, Table 4) and parsimony (Fig. 4) criteria. Both analyses reveal a varying degree of genetic relatedness for cultivars belonging to different species and

Fig. 2. The pattern of amplified simple sequence repeat (SSR) fragments obtained from pear cultivars under study using the primer pair NZ05g8, separated by polyacrylamide gel eletrophoresis (PAGE) and visualized by staining with ethidium bromide as described in the text. See Table 1 for the names of cultivars designated by numbers 1 to 28 . from different geographic origins. For the most part, cultivars are classified into clades as would be predicted from what is known about their genetic backgrounds. 
Table 3. Simple sequence repeat (SSR) fragments most useful for cultivar identification, designated by primer name and fragment size, separated by a hyphen.

\begin{tabular}{|c|c|c|c|}
\hline Cultivar name & Identifying fragments (bp) & Cultivar name & Identifying fragments (bp) \\
\hline Nijisseiki & NH006b1-198, NH021a-150, NH021a-313, NH027a-321 & AC Harrow Crisp & NH001c-356, NH001c-391 \\
\hline Hosui & NH006b1-453, NH025a-382 & AC Harrow Gold & NH001c-379, NH001c-399, NZ28f4-199 \\
\hline Kosui & NH001c-287 & NY 10352 & NB109a-320 \\
\hline Niitaka & NH006b1-292, NH021a-297, NH025a-387 & NY 10353 & NH001c-229, NH006b1-189, NH006b1-226, NH025a-84, \\
\hline Shinko & CH02B10-299, NH001c-199, NH001c-215 & & NH025a-336 \\
\hline \multirow{2}{*}{ Anjou } & $\begin{array}{l}\text { NH021a-209, NH025a-182, RLG1-1-220 } \\
\text { CH01F02-387, KA4b-416, NH006b1-221, NH006b1-280, }\end{array}$ & Kieffer & $\begin{array}{l}\text { NB109a-155, NB109a-265, NZ05g8-180, PS12A02-245, } \\
\text { PS12A02-295 }\end{array}$ \\
\hline & NH021a-204, NZ05g8-312, NZ05g8-345 & OHF 69 & NH027a-198, PS12A02-212 \\
\hline Bartlett & NH013a-192 & OHF 87 & NB105a-354, NH006b1-389, NH021a-231, NH021a-253 \\
\hline Bosc & NB105a-237, NH029a-292, NH029a-382 & OHF 333 & NB105a-482, NH027a-406, RLG1-1-485 \\
\hline Clapp Favorite & NB109a-230 & Winter Nelis & CH02B10-333, KA4b-85, NZ28f4-211, NZ28f4-221, \\
\hline Flemish Beauty & NH001c-221, NH001c-343 & & PS12A02-285 \\
\hline Magness & KA4b-160, NH013a-299, NH029a-279, NZ28f4-229 & Catillac & CH01F02-292, NB109a-200, NB109a-265, NH006b1-156, \\
\hline Moonglow & $\begin{array}{l}\text { KA4b-81, KA4b-227, KA4b-305, KA4b-388, NH001c-403, } \\
\text { PS12A02-220 }\end{array}$ & & $\begin{array}{l}\text { NH006b1-174, NH006b1-195, NH021a-246, NH027a-118, } \\
\text { NH027a-224, NZ02b1-273, NZ05g8-150 }\end{array}$ \\
\hline Obican Vodenac & $\begin{array}{l}\text { CH01F02-226, CH02B10-291, NH001c-204, NH013a-289, } \\
\text { NH013a-406, NH021a-239, NH021a-287, NH029a-266, } \\
\text { NH029a-373, NZ02b1-266, NZ02b1-466, NZ28f4-253 }\end{array}$ & PI 312151 & $\begin{array}{l}\text { NB109a-275, NH006b1-136, NH010a-145, NH010a-267, } \\
\text { NH013a-149, NH021a-278, NH027a-125, PS12A02-218, } \\
\text { RLG1-1-360, RLG1-1-376 }\end{array}$ \\
\hline Timpurii de Dimbovita & $\begin{array}{l}\text { CH02B10-167, CH02B10-338, CH02B10-356, KA4b-106, } \\
\text { NB105a-406 }\end{array}$ & Pyrus fauriei & $\begin{array}{l}\text { KA4b-404, NH006b1-443, NH006b1-473, NH010a-217, } \\
\text { NH010a-261, NH021a-134, NH027a-399, NZ02b1-338, }\end{array}$ \\
\hline Harrow Delight & NH013a-227, RLG1-1-170, RLG1-1-305 & & NZ05g8-175, PS12A02-320 \\
\hline Harvest Queen & NZ02b1-293, NZ02b1-333 & & \\
\hline
\end{tabular}

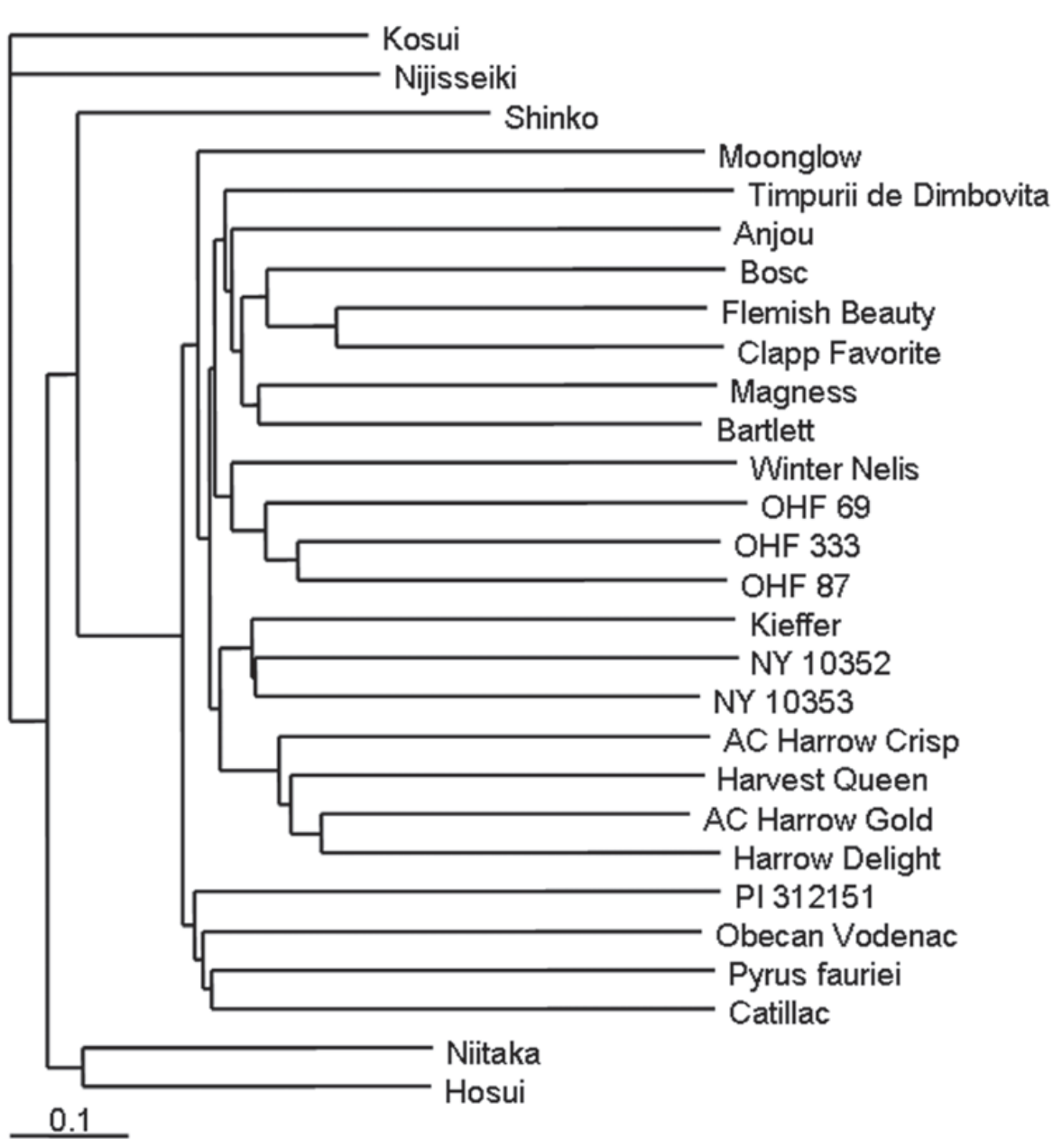

Fig. 3. Tree generated using the Fitch-Margoliash algorithm least squares criteria to identify an optimal tree. Distance is indicated by the horizontal bar at bottom left.

Four Canadian cultivars ('Harrow Delight', 'AC Harrow Crisp', 'AC Harrow Gold', and 'Harvest Queen') are clustered in the same clade with strong support, consistent with their known pedigrees (Hunter et al., 2002a, 2002b; Quamme and Spearman, 1983). The rootstock genotypes OHF 69, OHF 87, and OHF 333 also group together with moderate support. belong to the same grouping, reflecting their close genetic interrelationships. The cultivar 'Magness' is part of the same grouping, as expected from its $P$. communis ancestors 'Seckel' and 'Comice'. The interspecific hybrids NY 10352 and NY 10353 were found in a closely related subgroup (bootstrap support 74\%). Both NY selections, which originated from the cross $P$. communis $\times(P$. communis $\times P$. ussuriensis Maxim), are similar to 'Kieffer', an interspecific hybrid between P.serotina [sic] and putatively $P$. communis cultivar 'Bartlett' (Hedrick 1921).

Some predicted relationships were not supported by the trees. 'Catillac', a European cultivar, did not cluster with the other cultivated $P$. communis samples. Both 'Winter Nelis', originating from a $P$. communis seedling selection in Europe, and 'Moonglow', originating from a controlled cross between $P$. communis selections in North America, fail to cluster as might be expected from their $P$. communis backgrounds. Given the failure of the 'Winter Nelis' sample to produce the expected SSR fragment with primer set $\mathrm{K} 4 \mathrm{Ab}$, however, there is some doubt about the authenticity of the 'Winter Nelis' sample. Comparison of our sample with that from a specimen tree in the pear repository should clarify this issue. One subgroup contains two species [P. fauriei, PI 312151 (P. ussuriensis)] as well as the P. communis cultivar 'Catillac'. However, bootstrap support for these classifications is weak.

There was a clear separation of the P. pyrifolia Japanese cultivars from European and North American accessions of $P$. communis. According to pedigree information obtained from the Germplasm Resources Information Network (GRIN) of the United States Agriculture Research Service/NCGR-Corvallis Pyrus Catalog (www.ars-grin.gov/cor/catalogs/pyrcult), 'Hosui' and 'Kosui' originated from the same maternal parent 'Kikusui' (Table 1). With our SSR data, 'Hosui' groups close to 'Niitaka', although no pedigree relationship is known.

In summary, this study reports reproducible SSR data for 28 cultivars of the genus Pyrus 

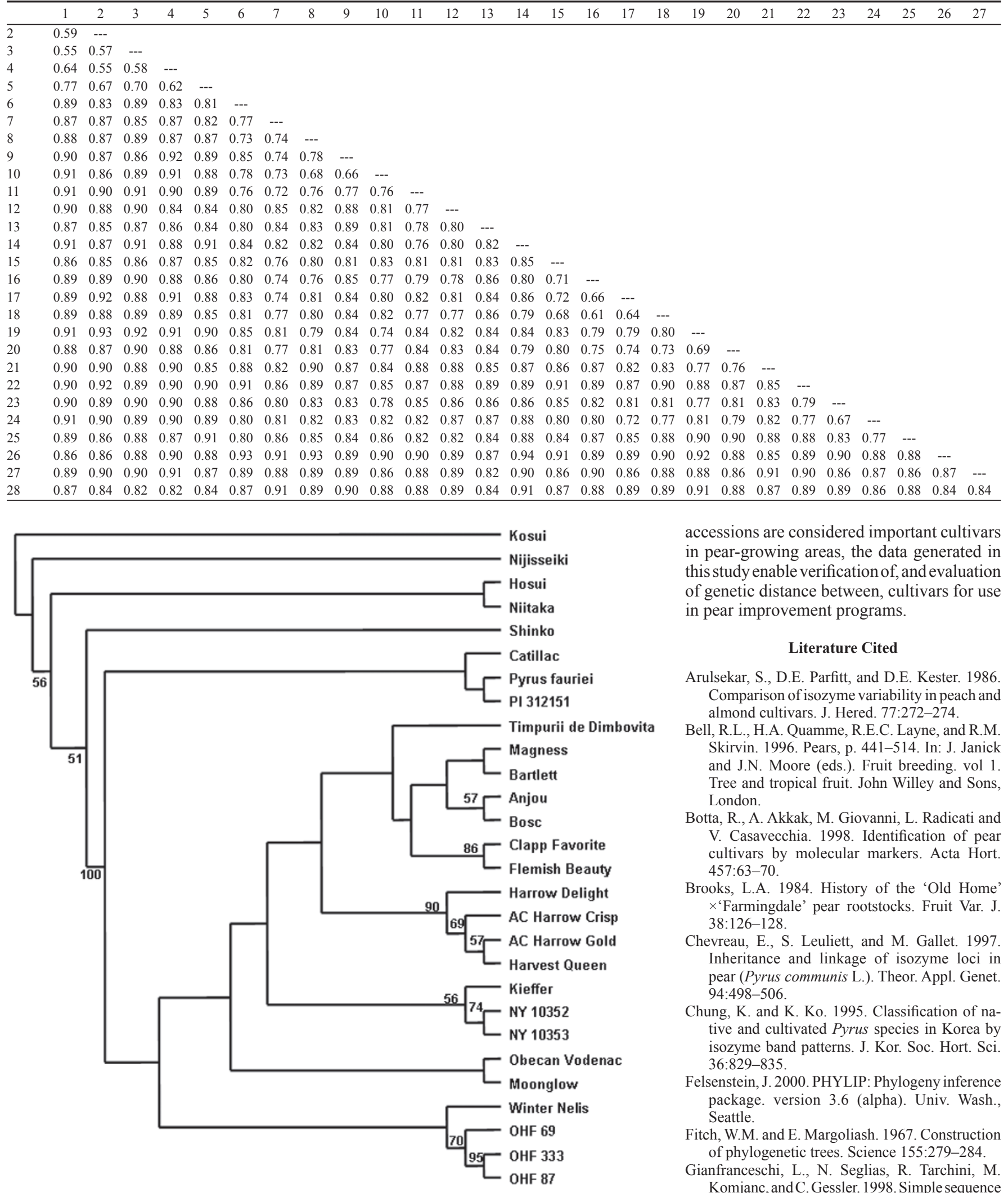

Fig. 4. Parsimony tree based on shared simple sequence repeat (SSR) fragments. Nodes found in $>50 \%$ of the trees generated from 1000 permuted data sets are indicated by numbers representing the bootstrap support value.

grown in North America. A small number of SSR markers uniquely identified every cultivar within our sample. Athough the statistical support for many clades is weak, the two trees generated by different methods are remarkably consistent. With a few exceptions cultivar relationships based on this method are confirmed by pedigree records. As these 28 accessions are considered important cultivars in pear-growing areas, the data generated in this study enable verification of, and evaluation of genetic distance between, cultivars for use in pear improvement programs.

\section{Literature Cited}

Arulsekar, S., D.E. Parfitt, and D.E. Kester. 1986 Comparison of isozyme variability in peach and almond cultivars. J. Hered. 77:272-274.

Bell, R.L., H.A. Quamme, R.E.C. Layne, and R.M. Skirvin. 1996. Pears, p. 441-514. In: J. Janick and J.N. Moore (eds.). Fruit breeding. vol 1. Tree and tropical fruit. John Willey and Sons, London.

Botta, R., A. Akkak, M. Giovanni, L. Radicati and V. Casavecchia. 1998. Identification of pear cultivars by molecular markers. Acta Hort. 457:63-70.

Brooks, L.A. 1984. History of the 'Old Home' $\times$ 'Farmingdale' pear rootstocks. Fruit Var. J. $38: 126-128$

Chevreau, E., S. Leuliett, and M. Gallet. 1997. Inheritance and linkage of isozyme loci in pear (Pyrus communis L.). Theor. Appl. Genet. 94:498-506.

Chung, K. and K. Ko. 1995. Classification of native and cultivated Pyrus species in Korea by isozyme band patterns. J. Kor. Soc. Hort. Sci. $36: 829-835$.

Felsenstein, J. 2000. PHYLIP: Phylogeny inference package. version 3.6 (alpha). Univ. Wash., Seattle.

Fitch, W.M. and E. Margoliash. 1967. Construction of phylogenetic trees. Science 155:279-284.

Gianfranceschi, L., N. Seglias, R. Tarchini, M. Komjanc, and C. Gessler. 1998. Simple sequence repeats for the genetic analysis of apple. Theor Appl. Genet. 96:1069-1076.

Guilford, P., S. Prakash, J.M. Zhu, E. Rikkerink, S. Gardiner, H. Basset, and R. Forster. 1997. Microsatellites in Malus $\times$ domestica (apple): Abundance, polymorphism and cultivar identification. Theor. Appl. Genet. 94:249-254.

Hedrick, U.P. 1921. The pears of New York. Rpt. NY Agr. Expt. Sta. 1921. JB Lyon Co. Printers, Albany, N.Y.

HortScience Vol. 41(2) April 2006 
Hokanson, S.C., A.K. Szewc-McFadden, W.F Lamboy, and J.R. McFerson. 1998. Microsatellite (SSR) markers reveal genetic identities, genetic diversity and relationships in a Malus $\times$ domestica borkh. core subset collection. Theor. Appl. Genet. 97:671-683.

Hunter, D.M., F. Kappel, H.A. Quamme, and G. Bonn. 2002a. 'AC Harrow Crisp' pear. HortScience 37(1):227-229

Hunter, D.M., F. Kappel, H.A. Quamme, and G. Bonn. 2002b. 'AC Harrow Gold' Pear. HortScience 37(1):224-226.

Iketani, H., A. Kazuyuki, T. Yamamoto, K. Kotobuki, Y. Sato, T. Saito, O. Terai, N. Matsuta, and T. Hayashi. 2001. Mapping of disease-related genes in Japanese pear using a molecular linkage map with RAPD markers. Breeding Sci. 51:179-184.

Kikuchi, A. 1948. Horticulture of fruit trees. vol. 1. Yokendo, Tokyo.

Kresovich, S. and J.R. McFerson. 1992. Assessment and management of plant genetic diversity: Considerations of intra- and inter-specific variation. Field Crops Res. 29:185-204.
Mellersh, C. and J. Sampson. 1993. Simplifying detection of microsatellite length polymorphisms. BioTechniques 15:582-584.

Messeguer, R., P.Arus, and M. Carrera. 1987. Identification of peach cultivars with pollen isozymes. Scientia Hort. 31:107-117.

Monte-Corvo, L., L. Goulão, and C. Oliveira. 2001. ISSR analysis of cultivars of pear and suitability of molecular markers for clone discrimination. J. Amer. Soc. Hort. Sci. 126(5):517-522.

Oliveira, C.M., M. Mota, L. Monte-Corvo, L. Goulão, and D.M. Silva. 1999. Molecular typing of Pyrus based on RAPD markers. Scientia Hort. 79:163-174.

Quamme, H.A. and G.A. Spearman. 1983. 'Harvest Queen' and 'Harrow Delight' pear. HortScience 18:770-772.

Shen, T. 1980. Pears in China. HortScience 15:13-17.

Sosinski, B., M. Gannavarapu, L.D. Hager, L.E. Beck, G.J. King, C.D. Ryder, S. Rajapakse, W.V. Baird, R.E. Ballard, and A.G. Abbott. 2000. Characterization of microsatellite markers in peach [Prunuspersica (L.) Batsch]. Theor.Appl.
Genet. 101:421-428.

Westwood, M.N. 1982. Pear germplasm of the new national clonal repository: Its evaluation and use. Acta Hort. 124:57-65.

Yamamoto, T., T. Kimura, Y. Sawamura, K. Kotobuki, Y. Ban, T. Hayashi, and N. Matsuta. 2001. SSR isolated from apple can identify polymorphism and genetic diversity in pear. Theor. Appl. Genet. 102:865-870.

Yamamoto, T., T. Kimura, Y. Sawamura, T. Manabe, K. Kotobuki, T. Hayashi, Y. Ban, and N. Matsuta. 2002a. Simple sequence repeats for genetic analysis in pear. Euphytica 124:129-137.

Yamamoto, T., T. Kimura, M. Shoda, T. Imai, T. Saito, Y. Sawamura, K. Kotobuki, T. Hayashi, and N. Matsuta. 2002b. Genetic linkage maps constructed by using an interspecific cross between Japanese and European pears. Theor. Appl. Genet. 106(1):9-18.

Yamamoto, T., T. Kimura, M. Shoda, Y. Ban, T. Hayashi, and N. Matsuta. 2002c. Development of microsatellite markers in the Japanese pear (Pyrus pyrifolia Nakai). Mol. Ecol. Notes 2:14-16. 